\title{
Influence of surgical treatment of selected malignant tumours on gait kinematics - a pilot study
}

\author{
DOI: https://doi.org/10.5114/pq.2018.79988
}

\author{
Anna Latajka', Marek Woźniewski², Iwona Malicka² \\ ${ }^{1}$ Lower Silesian Oncology Centre in Wroclaw, Wroclaw, Poland \\ ${ }^{2}$ Faculty of Physiotherapy, University School of Physical Education in Wroclaw, Wroclaw, Poland
}

Abstract

Introduction. Assessment of the influence of surgical treatment of selected malignant tumours on gait kinematics.

Methods. The study involved 115 patients of the Lower Silesian Oncology Centre in Wroclaw, Poland (95 women and 20 men), mean age $58.39 \pm 11.14$ years, treated surgically for diagnosed cancer (group A: breast cancer; group B: reproductive cancer; group C: gastrointestinal cancer). Gait measurements were performed with the BTS G-Walk accelerometer before and after the surgery $\left(5^{\text {th }}-6^{\text {th }}\right.$ postoperative day). The $t$-test for dependent samples and analysis of variance - least significant difference test - were applied.

Results. A significant decrease in cadence and walking speed was observed, by $7.9 \%(p<0.001)$ and $17.5 \%(p<0.001)$ in group B, and by $4.0 \%(p<0.001)$ and $11.7 \%(p<0.001)$ in group $C$, respectively. Additionally, there was an upward trend for symmetry of pelvic tilt in the sagittal plane $(67.9 \%$ vs. $76.7 \%, p=0.09)$ in group $\mathrm{A}$, and a significant difference in pelvic deflections in the frontal plane $(94.8 \%$ vs. $88.1 \%, p=0.02)$ in group C. Statistically significant differences were found in walking cadence between groups A and B ( $p=0.002)$, and in walking speed between group A and groups B and C (group A vs. B: $p<0.001$; group A vs. C: $p=0.03$ )

Conclusions. In patients treated surgically for reproductive system and gastrointestinal cancers, a decrease in time and space parameters of gait was demonstrated. Additionally, in patients treated for gastrointestinal cancers, the effect of surgical treatment on gait kinematics was found.

Key words: cancer, surgical treatment, gait kinematics, gait cadence, gait disorders

\section{Introduction}

In Poland, as well as worldwide, cancer is a serious health problem [1]. It is recognized to be a severe chronic disease [2], and the risk of getting cancer increases with age - ca. $60 \%$ of cancers in women and ca. $70 \%$ of cancers in men develop after the age of 60 [3]. In Poland, life expectancy is currently 75.8 years; it is expected that in the coming years, the general structure of the Polish society will include $18.2 \%$ of elderly people [3]. The problem of cancer largely affects older people, in whom the need to ensure mobility becomes very important, both for social and ethical reasons.

Surgery is the oldest and one of the most effective means of treating cancer. Most surgical operations, however, are characterized by the extent related to the need to remove the tumour together with a margin of healthy tissue, as well as with surrounding lymph vessels and nodes. Thus, they lead to complications and functional disorders [4].

The most common malignant tumour in women is breast cancer. Damage to anatomical structures during surgery may contribute to upper body quadrant dysfunctions [5, 6]. Disturbances of chest wall muscle balance and the resulting disorders of postural muscle balance may lead to postural defects - deepening of thoracic kyphosis and lumbar lordosis, which may in turn contribute to the occurrence of low back pain [7]. Low back pain is often accompanied by changes in gait; during walking, trunk muscles that support stability, rotation, and lifting of the pelvis and its movements in the sagit- tal plane are activated. Decreased walking velocity and pelvis rotation asymmetry may occur $[8,9]$.

High incidence among women is also observed for reproductive cancers (endometrial, cervical, and ovarian cancers). Surgical treatment in the lower abdomen may contribute to restricted hip mobility and flexion contracture [10]. Hip flexion contracture causes increased pelvic anteversion during the support phase and, together with pain after surgery, can result in crouch gait. Additionally, a reduced range of hip movement is also associated with reduced walking speed [11].

Gastrointestinal cancers, in particular colorectal cancer, are also a serious epidemiological problem nowadays. Abdominal surgery is associated with damage and weakness of abdominal muscles, which may lead to deepening of lumbar lordosis, and may be a factor causing lower back pain [12]. The patient usually leans forward, adopting a hunched posture, and the walk becomes cautious, usually with small steps. Thoracic and pelvic movements are reduced. As a consequence, gait disturbances may occur, in terms of both spatiotemporal and kinematic parameters [8].

Gait is a natural human need. The possibility of independent and proper free movement is a priority in daily functioning of patients with malignant tumours. Many musculoskeletal system and nervous system diseases cause an abnormal gait pattern or completely prevent walking. The reasons for the occurrence of a pathological gait pattern may be limitation of joint mobility, deformities, injuries, decreased muscle strength, neuromuscular disorders, and pain. A disturbed gait pattern

Correspondence address: Anna Latajka, Dolnośląskie Centrum Onkologii, pl. Hirszfelda 12, 53-413 Wrocław, Poland, e-mail: latajka.anna@dco.com.pl

Received: 2018.09.25

Accepted: 2018.11.20

Citation: Latajka A, Woźniewski M, Malicka I. Influence of surgical treatment of selected malignant tumours on gait kinematics - a pilot study. Physiother Quart. 2018;26(4):33-39; doi: https://doi.org/10.5114/pq.2018.79988. 
may not only limit the efficiency of walking and cause increase in energy expenditure, but also result in secondary, incorrect compensatory reactions that can be fixed $[13,14]$. Therefore, it is important to take appropriate measures to detect possible functional disorders, which in turn contribute to a greater risk of falls [6], particularly in elderly people [15]. Gait is considered to be one of the most reliable parameters reflecting the patient's overall condition and a factor predicting safe movement in daily life [15]. Studenski et al. [16] suggest further that gait speed along with variables such as sex and age may determine the goals of medical care for older people.

Literature review showed a small number of publications on gait analysis in patients treated for cancers [17-19]. The available studies concern mainly patients after hip or knee arthroplasty and those suffering from Parkinson's disease, reporting primarily changes in the spatiotemporal and kinematic parameters of gait [20-25].

Gait analysis with the use of devices with gyroscopic mechanisms that analyse gait, along with simultaneous measurement of gait speed, loading time of individual limbs, and three-plane pelvic tilts, has been available so far only under the conditions of complex machinery and space restrictions, e.g. in specialized laboratories. Technological progress, and thus minimization of devices and the use of sensitive GPS receivers, allow currently to carry out the analyses in natural settings and under conditions often not available so far, including hospital environment.

In connection with the above, the aim of this study was to assess the influence of surgical treatment of selected malignant tumours on gait kinematics.

\section{Subjects and methods}

\section{Study group}

The study group comprised 115 patients of the Lower Silesian Oncology Centre in Wroclaw, Poland (95 women and 20 men) of the mean age of $58.39 \pm 11.14$ years, treated surgically for diagnosed cancer. The mean body height was $164.20 \pm 7.48 \mathrm{~cm}$, mean body weight $74.29 \pm 15.69 \mathrm{~kg}$ and mean BMI $27.49 \pm 5.23 \mathrm{~kg} / \mathrm{m}^{2}$.

The patients were divided in a targeted manner into 3 groups, depending on the area of the surgery performed:

- Group A ( $n=37$, women): patients treated surgically for breast cancer - chest surgery (mastectomy, mastectomy with simultaneous implant-based reconstruction, quadrantectomy with lymphadenectomy).

- Group B ( $n=44$, women): patients treated surgically for reproductive cancer (endometrial cancer, ovarian cancer, cervical cancer) - surgery in the area of lesser pelvis (gynaecologic oncology procedures with an open incision in the abdomen - abdominal surgery).

- Group C ( $n=34 ; 14$ women, 20 men): patients treated surgically for gastrointestinal cancer (gastric cancer, colorectal cancer, rectal cancer) - extensive surgeries involving long abdominal incisions (oncological laparotomies).

Detailed characteristics of the studied groups are presented in Table 1.

\section{Methods}

Each patient was tested twice: before the surgery and on the day of discharge from hospital (5-6 days after surgery). In all patients, gait measurements on the distance of $20 \mathrm{~m}$ were performed with the BTS G-Walk accelerometer.

The G-Walk is a wireless system consisting of an inertial sensor composed by a triaxial accelerometer, a magnetic sensor, and a triaxial gyroscope.

A sensor (BTS G-Walk, sensor) was placed on the patient's body with a belt at the level of lumbar spine (in the area of the L4-L5 intervertebral space), and the patient's task was to walk $10 \mathrm{~m}$ in one direction at their own speed, then to turn around and walk $10 \mathrm{~m}$ back. During both tests, the patient had the same footwear.

The collected data were then sent via Bluetooth to a computer and processed with the dedicated BTS G-Walk software. BTS G-Walk accelerometer is a system with many applications, dedicated to diagnosis and research [26]. The device acquires accurate and objective (non-normalized and normalized) kinematic data during the walk. On the basis of literature reports concerning BTS G-Walk [26-32], the following spatiotemporal gait parameters were evaluated:

- walking cadence (steps/min) - number of steps per minute;

- walking speed $(\mathrm{m} / \mathrm{s})$ - the average instantaneous speed within the gait cycle;

- symmetry index (\%) - which quantifies how much the profile of the right curve is similar to the profile of the left curve; ideally, if the two curves are perfectly overlapping, the index is 100 and it means that the two curves have the same value frame by frame;

- symmetry of pelvis position in 3 planes:

a) pelvic tilt index (\%) - symmetry of pelvic tilt in the sagittal plane,

b) pelvic obliquity index (\%) - symmetry of pelvic obliquity in the coronal plane,

c) pelvic rotation index (\%) - symmetry of pelvic rotation in the transverse plane.

For the pelvic tilt, values higher than 40 can be considered as normal ones. For the pelvic obliquity and rotation angles, the normal value is $80-100$ (according to the guidelines of the manufacturer, BTS Bioengineering, Milan, Italy).

The BTS G-Walk device uses the mathematical function of correlation applied to the two curves:

$$
\text { Symmetric index }=(\operatorname{corr}+1) \times 100 / 2
$$

where: corr is the Pearson correlation coefficient between the mean left and right normalized anteroposterior acceleration signal (according to the manufacturer's guidelines).

Table 1. Statistical characteristics of age and somatic parameters of the studied groups (means $+S D$ )

\begin{tabular}{|l|c|c|c|c|}
\hline Feature & $\begin{array}{c}\text { Total } \\
(n=115)\end{array}$ & $\begin{array}{c}\text { Group A } \\
(n=37)\end{array}$ & $\begin{array}{c}\text { Group B } \\
(n=44)\end{array}$ & $\begin{array}{c}\text { Group C } \\
(n=34)\end{array}$ \\
\hline Age (years) & $58.39 \pm 11.14$ & $57.57 \pm 12.16$ & $55.77 \pm 10.26$ & $62.68 \pm 10.07$ \\
\hline Body weight $(\mathrm{kg})$ & $74.29 \pm 15.69$ & $76.78 \pm 18.48$ & $73.43 \pm 16.14$ & $72.68 \pm 11.29$ \\
\hline Body height $(\mathrm{cm})$ & $164.20 \pm 7.48$ & $163.32 \pm 6.92$ & $162.64 \pm 5.39$ & $167.18 \pm 9.49$ \\
\hline BMI $\left(\mathrm{kg} / \mathrm{m}^{2}\right)$ & $27.49 \pm 5.23$ & $28.62 \pm 5.68$ & $27.72 \pm 5.81$ & $25.97 \pm 3.39$ \\
\hline
\end{tabular}




\section{Statistical analysis}

Statistical calculations were performed with the use of the Statistica software. Means and standard deviations were determined. The normality of distribution was verified with Shapiro-Wilk test, and the homogeneity of variance with Levene's test. The $t$-test was performed (intragroup analysis), and additionally, analysis of variance - with post-hoc testing - with the least significant difference test for comparison of differences dependent on surgery (intergroup analysis) was conducted. The level of statistical significance for the relationships under investigation was set at $p<0.05$.

\section{Ethical approval}

The research related to human use has been complied with all the relevant national regulations and institutional policies, has followed the tenets of the Declaration of Helsinki, and has been approved by the Local Bioethics Committee at the University of Physical Education in Wroclaw, Poland (consent No. 28/2018).

\section{Informed consent}

Informed consent has been obtained from all individuals included in this study.

\section{Results}

In the study group, there was observed a decrease in walking cadence by $4.6 \%$ compared with the first measurement, and a decrease in walking speed by $11.7 \%$ (Table 2 ).

For the group of patients after breast cancer surgery (group A), the decreases in walking cadence and speed were not statistically significant. In the groups of patients treated surgically for reproductive cancer (group B) and gastrointestinal cancer (group C), statistically significant differences were found, in terms of both gait cadence and speed. The gait cadence for group $B$ in the second test decreased by $7.9 \%$ in relation to the mean of the first measurement, and the speed decreased by $17.5 \%$ compared with the pre-surgery mean. In group C, gait cadence decreased by $4.0 \%$ and walking speed decreased by $11.7 \%$. Detailed data are presented in Table 2.

The gait symmetry index did not show statistically significant differences either for all the studied patients or in the particular groups.

In the study group, the change in pelvis motion symmetry between the two measurements (preoperative test vs. postoperative test) was statistically significant for the coronal plane (94.2\% vs. $89.7 \%, p=0.03)$. There were no significant differences for the movement of pelvis in the sagittal or transverse planes (Table 3).

Table 2. Gait cadence and walking speed in the studied groups

\begin{tabular}{|l|c|c|c|}
\cline { 2 - 4 } \multicolumn{1}{c|}{} & Preoperative test $($ mean $\pm S D)$ & Postoperative test $($ mean $\pm S D)$ & $p$ \\
\hline Gait cadence $(n=115)($ steps/min) & $112.47 \pm 11.95$ & $107.24 \pm 12.89$ & $<0.001^{*}$ \\
\hline Group A $(n=37)$ & $114.53 \pm 12.17$ & $112.90 \pm 10.06$ & 0.34 \\
\hline Group B $(n=44)$ & $116.06 \pm 7.48$ & $106.91 \pm 12.05$ & $<0.001^{*}$ \\
\hline Group C $(n=34)$ & $105.75 \pm 14.22$ & $101.52 \pm 14.87$ & $<0.001^{*}$ \\
\hline Walking speed $(n=115)(\mathrm{m} / \mathrm{s})$ & $1.11 \pm 0.18$ & $0.98 \pm 0.20$ & $<0.001^{*}$ \\
\hline Group A $(n=37)$ & $1.08 \pm 0.21$ & $1.04 \pm 0.22$ & 0.10 \\
\hline Group B $(n=44)$ & $1.14 \pm 0.15$ & $0.94 \pm 0.18$ & $<0.001^{*}$ \\
\hline Group C $(n=34)$ & $1.11 \pm 0.19$ & $0.98 \pm 0.21$ & $<0.001^{*}$ \\
\hline
\end{tabular}

* statistically significant results

Table 3. Symmetry of pelvic motion in the studied groups

\begin{tabular}{|c|c|c|c|}
\hline & & & \\
\hline & Preoperative test (mean $\pm S D$ ) & Postoperative test (mean $\pm S D$ ) & $p$ \\
\hline Pelvic tilt index $(n=115)(\%)$ & $65.92 \pm 23.96$ & $69.85 \pm 23.13$ & 0.13 \\
\hline Group A $(n=37)$ & $67.93 \pm 27.87$ & $76.71 \pm 18.58$ & 0.09 \\
\hline Group B $(n=44)$ & $69.12 \pm 19.85$ & $71.70 \pm 21.98$ & 0.52 \\
\hline Group C $(n=34)$ & $59.74 \pm 24.96$ & $60.12 \pm 27.24$ & 0.93 \\
\hline Pelvic obliquity index $(n=115)(\%)$ & $94.21 \pm 13.57$ & $89.73 \pm 19.54$ & $0.03^{*}$ \\
\hline Group A $(n=37)$ & $97.20 \pm 5.31$ & $91.91 \pm 19.17$ & 0.11 \\
\hline Group B $(n=44)$ & $91.11 \pm 20.66$ & $89.10 \pm 21.25$ & 0.46 \\
\hline Group C $(n=34)$ & $94.85 \pm 7.51$ & $88.15 \pm 19.16$ & $0.02^{*}$ \\
\hline Pelvic rotation index $(n=115)(\%)$ & $86.05 \pm 21.90$ & $83.40 \pm 24.92$ & 0.35 \\
\hline Group A $(n=37)$ & $89.46 \pm 15.14$ & $82.17 \pm 29.28$ & 0.20 \\
\hline Group B $(n=44)$ & $85.98 \pm 25.17$ & $84.77 \pm 23.74$ & 0.81 \\
\hline Group C $(n=34)$ & $82.43 \pm 24.80$ & $83.03 \pm 23.29$ & 0.89 \\
\hline
\end{tabular}

* statistically significant results 
Table 4. Significance of differences between groups for gait cadence

Gait cadence (steps/min): differences between preoperative test and postoperative test ( $p$ values)

\begin{tabular}{|c|c|c|c|}
\hline & $\begin{array}{c}\text { Group A } \\
(\text { mean }=1.63)\end{array}$ & $\begin{array}{c}\text { Group B } \\
(\text { mean = 9.15) }\end{array}$ & $\begin{array}{c}\text { Group C } \\
(\text { mean }=4.22)\end{array}$ \\
\hline Group A & & $0.002^{*}$ & 0.31 \\
\hline Group B & $0.002^{*}$ & & 0.05 \\
\hline Group C & 0.31 & 0.05 & \\
\hline
\end{tabular}

* statistically significant results

Table 5. Significance of differences between groups for walking speed

Walking speed $(\mathrm{m} / \mathrm{s})$ : differences between preoperative test and postoperative test ( $p$ values)

\begin{tabular}{|c|c|c|c|}
\hline & $\begin{array}{c}\text { Group A } \\
(\text { mean }=0.04)\end{array}$ & $\begin{array}{c}\text { Group B } \\
(\text { mean }=0.19)\end{array}$ & $\begin{array}{c}\text { Group C } \\
(\text { mean }=0.12)\end{array}$ \\
\hline Group A & & $<0.001^{*}$ & $0.03^{*}$ \\
\hline Group B & $<0.001^{*}$ & & 0.10 \\
\hline Group C & $0.03^{*}$ & 0.10 & \\
\hline
\end{tabular}

* statistically significant results

Considering the particular groups, in the group of women treated surgically for breast cancer, an upward trend was found for the symmetry of pelvic tilt in the sagittal plane $(67.9 \%$ vs. $76.7 \%, p=0.09$ ), whereas no significant differences were observed in the other groups. Symmetry of pelvic motion in the coronal plane was significantly different in the group of patients treated surgically for gastrointestinal cancer $(94.8 \%$ vs. $88.1 \%, p=0.02$ ), while no significant differences were noted for the symmetry of pelvic rotation in the transverse plane (Table 3).

For each group, the range of changes of the above parameters between the tests was also calculated, with the first measurement assumed as the patient's standard. The differences between the groups were significant for gait cadence (group A vs. B; Table 4) and for walking speed (group A vs. groups B and C; Table 5), while no significant differences were found for the gait symmetry index and pelvic position, irrespective of the tested plane.

\section{Discussion}

Walking is a complex activity connected with efficient functioning of several, e.g. musculoskeletal, cardiovascular, pulmonary, and neurological systems [33]. Cancer and its treatment may contribute to psychophysical disorders and changes in the above systems, leading to limitation of physical activity and a decrease in the quality of life.

This study showed a significant decrease in gait cadence and walking speed of patients treated surgically for reproductive and gastrointestinal cancer. The decrease of gait cadence in the group of women treated for reproductive cancer was $9.15 \mathrm{steps} / \mathrm{min}$, and the decrease of walking speed was $0.19 \mathrm{~m} / \mathrm{s}$. In patients diagnosed with gastrointestinal cancer the values were $4.22 \mathrm{steps} / \mathrm{min}$ and $0.13 \mathrm{~m} / \mathrm{s}$, correspondingly. Walking speed is considered to be the most important gait parameter.

The results obtained by Perera et al. [34] suggest that a change in walking speed by $0.05 \mathrm{~m} / \mathrm{s}$ is small but clinically meaningful, while that exceeding $0.10 \mathrm{~m} / \mathrm{s}$ is significant for mobility. Therefore, it can be concluded that surgical treatment of the aforementioned cancers caused a significant change in the mobility of the treated persons.
Walking speed is also considered a predictive fall risk factor. Quach et al. [35] and Van Kan et al. [36] showed that the lowest risk of falls occurs at the walking speed of $1-1.3 \mathrm{~m} / \mathrm{s}$. Quach et al. [35] stated that both lower $(<0.6 \mathrm{~m} / \mathrm{s})$ and higher $(>1.3 \mathrm{~m} / \mathrm{s})$ walking speeds significantly increase that risk. Van Kan et al. [36], in turn, determined the limit value of walking speed to be $1.0 \mathrm{~m} / \mathrm{s}$, not only recognizing it as significant in regard to a greater risk of falls, but also considering it to be a predictor of hospitalization and mortality. The presented study showed mean values of walking speed in the second test equal $0.94 \mathrm{~m} / \mathrm{s}$ and $0.98 \mathrm{~m} / \mathrm{s}$ for patients treated for reproductive cancer and for those treated for gastrointestinal cancer, respectively. Those groups were significantly different in the intergroup comparison with the patients treated surgically for breast cancer. Significant differences both in gait cadence and in walking speed were found in the group of women treated surgically for reproductive cancer; patients operated for gastrointestinal cancer were characterized with significant differences in walking speed.

In view of the above, it is important to implement appropriate physiotherapeutic measures that will allow patients to remain independent in basic activities of their daily living and to quickly return to an active social life.

Additionally, changes in the symmetry of pelvic position were observed in this study. A significant change was noted for coronal plane in patients treated surgically for gastrointestinal cancer. Pelvic motion within the coronal plane is a direct factor of minimizing vertical displacement of the body centre of mass [37]. In the case of patients treated for gastrointestinal cancer, antalgic posture and gait may have occurred (thoracic kyphosis with flexion of the hips and knees), which translated into a change in gait. Even a slight restriction of hip range of motion may disturb the normal gait pattern. Hip extension is required at the end of the stance phase. If the trail limb is not straightened in the hip joint during the terminal stance phase, the efficiency of swing decreases. Hip joint range of motion restriction therefore forces shortening of stride length, which in turn requires reduction of the range of extension movement at the hip joint [38]. This change may have an impact on the risk of falls in that group of patients [39].

Among women after breast cancer surgery, the observed trend of changes within the sagittal plane (increase in pelvic 
tilt symmetry) may translate into the stride length and be related to the walking speed. In that group, however, no significant changes in cadence or walking speed were found. The gait in women treated for breast cancer may have therefore become more conservative, which may be related to the selfperception. Sadeghi et al. [40] define gait symmetry as a consistent activity of lower limbs, during which the upper part of the body takes on stabilizing functions. Breast cancer surgery may cause postural freezing, thus increasing the symmetry. On the basis of the results obtained, it can be concluded that the group of women surgically treated for breast cancer is at the lowest risk of falling. However, population studies have shown that the risk of 2 or more falls within 1 year is $27 \%$ higher in postmenopausal women treated for breast cancer compared with healthy women [41].

Falls, however, are caused multifactorially; the factors can be divided into internal (associated with reduced fitness of the body) and external (independent of the aging process of the body). Internal factors include diseases, both acute and chronic [42]. Owing to the above, malignant tumours and their treatment are also mentioned among the reasons for the increased risk of falls. Usually, the relationship between complications and functional disorders resulting from oncological treatment and fall risk factors is mentioned. Among patients treated for cancer, reduction in bone density, decreased muscle strength, cardiorespiratory diseases, chemotherapy-induced neuropathies, fatigue and pain, as well as psychiatric disorders are observed both immediately after treatment and many years later [41, 43, 44]. Those disorders can largely affect the risk of falling.

Falls constitute a serious health problem, related with not only physical injuries, but also psychological consequences. It has been found that $48 \%$ of people who fall at least once are afraid of falling again, and $28 \%$ of people decrease their daily activity for this reason [44]. Therefore, in-depth examination of the causes of falls is needed. That is a particularly important problem among patients treated for malignant tumours, whose falls are usually multifactorial and occur more often compared with the corresponding age group without cancer history [45-48].

Knowledge of the occurrence of gait disturbances depending on the extent and site of surgery can therefore be helpful in developing methods for rehabilitation of patients, with the emphasis on obtaining improved balance and coordination. Fall risk reduction will consequently increase physical activity of patients after cancer surgery, which is of particular importance also for preventing side effects of cancer treatment.

\section{Conclusions}

1. In the group of patients operated on for reproductive and gastrointestinal cancer, a decrease in spatiotemporal gait parameters was demonstrated.

2. In the group of patients operated on for gastrointestinal cancer, a significant difference in symmetry of pelvic tilts in the coronal plane was observed.

3. The group of patients operated on for reproductive cancer is characterized by the greatest reduction of spatiotemporal gait parameters compared with the patients after gastrointestinal or breast cancer surgery.

4. Gait variability in cancer patients, which may translate into an increase in instability, indicates the need to prepare the patients to safely leave hospital environment.

\section{Disclosure statement}

No author has any financial interest or received any financial benefit from this research.

\section{Conflict of interest}

The authors state no conflict of interest.

\section{References}

1. Tuchowska P, Worach-Kardas H, Marcinkowski JT. The most frequent malignant tumors in Poland - the main risk factors and opportunities to optimize preventive measures [in Polish]. Probl Hig Epidemiol. 2013;94(2):166-171.

2. Topór-Mądry R. Chronic diseases. Burden, quality of life and economic consequences [in Polish]. Zdr Publ Zarządz. 2011;9(1):25-49;doi:10.4467/20842627OZ.11.002.0339.

3. Didkowska J. Epidemiology of malignant tumours in Poland [in Polish]. In: Meder J (ed.), Basics of clinical oncology [in Polish]. Warszawa: CMKP; 2011; 5-17.

4. Woźniewski $M$. Is rehabilitation needed in oncology? [in Polish]. In: Kabsch A, Wiernicka M (eds.), Progress in oncological rehabilitation [in Polish]. Poznań: Ośrodek Wydawnictw Naukowych; 2010; 18-26.

5. Lee TS, Kilbreath SL, Refshauge KM, Herbert RD, Beith JM. Prognosis of the upper limb following surgery and radiation for breast cancer. Breast Cancer Res Treat. 2008;110(1):19-37; doi: 10.1007/s10549-007-9710-9.

6. Zak M, Biskup M, Macek P, Krol H, Krupnik S, Opuchlik A. Identifying predictive motor factors for falls in postmenopausal breast cancer survivors. PloS One. 2017; 12(3):e0173970; doi: 10.1371/journal.pone.0173970.

7. Drzał-Grabiec J, Rachwał M, Walicka-Cupryś K. Body posture in women after mastectomy [in Polish]. Onkol Pol. 2013;16(1):11-15.

8. Lamoth CJ, Meijer OG, Daffertshofer A, Wuisman PI, Beek PJ. Effects of chronic low back pain on trunk coordination and back muscle activity during walking: changes in motor control. Eur Spine J. 2006;15(1):23-40; doi: 10.1007/s00586-004-0825-y.

9. Bąk K, Czupryna K, Nowotny-Czupryna O, Wróblewska E. Gait of people with low back pain [in Polish]. Ann Acad Med Siles. 2009;63(5):56-64.

10. Karowicz-Bilińska A, Sikora A, Estemberg D, Brzozowska M, Berner-Trąbska M, Kuś E, et al. The role of physiotherapy in selected gynecological disorders. Ginekol Pol. 2010;81(9):708-711.

11. Nonaka H, Mita K, Watakabe M, Akataki K, Suzuki N, Okuwa T, et al. Age-related changes in the interactive mobility of the hip and knee joints: a geometrical analysis. Gait Posture. 2002;15(3):236-243; doi: 10.1016/S09666362(01)00191-6.

12. Lewit K, Olsanska S. Clinical importance of active scars: abnormal scars as a cause of myofascial pain. J Manipulative Physiol Ther. 2004;27(6):399-402; doi: 10.1016/j. jmpt.2004.05.004.

13. Syczewska M. Gait in the image of laboratory analysis [in Polish]. Ortop Traumatol Rehabil. 2001;3(4):484-486.

14. Drużbicki M, Szymczyk D, Snela S, Dudek J, Chuchla M. Objective, quantitative methods of gait analysis in clinical practice [in Polish]. Prz Med Uniw Rzesz. 2009;4:356362.

15. Manikowska F, Hojan $K$, Chen PJ, Jóźwiak M, Jóźwiak $A$. The gait pattern in post-menopausal women. Pilot study. Ortop Traumatol Rehabil. 2013;15(6):575-583; doi: 10.5604/15093492.1091513. 
16. Studenski S, Perera S, Patel K, Rosano C, Faulkner K, Inzitari $\mathrm{M}$, et al. Gait speed and survival in older adults. JAMA.2011;305(1):50-58; doi:10.1001/jama.2010.1923.

17. Huang MH, Shilling T, Miller KA, Smith K, LaVictoire K. History of falls, gait, balance, and fall risks in older cancer survivors living in the community. Clin Interv Aging. 2015;10:1497-1503; doi: 10.2147/CIA.S89067.

18. Huang MH, Lytle T, Miller KA, Smith K, Fredrickson K. History of falls, balance performance, and quality of life in older cancer survivors. Gait Posture. 2014;40(3):451456; doi: 10.1016/j.gaitpost.2014.05.015.

19. Pamoukdjian F, Lévy V, Sebbane G, Boubaya M, Landre T, Bloch-Queyrat C, et al. Slow gait speed is an independent predictor of early death in older cancer outpatients: results from a prospective cohort study. J Nutr Health Aging. 2017;21(2):202-206; doi: 10.1007/s12603016-0734-x.

20. Kolk S, Minten MJ, van Bon GE, Rijnen WH, Geurts AC, Verdonschot N, et al. Gait and gait-related activities of daily living after total hip arthroplasty: a systematic review. Clin Biomech. 2014;29(6):705-718; doi: 10.1016/j.clinbiomech.2014.05.008.

21. Komnik I, Weiss S, Fantini Pagani CH, Potthast W. Motion analysis of patients after knee arthroplasty during activities of daily living - a systematic review. Gait Posture. 2015;41(2):370-377; doi:10.1016/j.gaitpost.2015.01.019.

22. Sosdian L, Dobson F, Wrigley TV, Paterson K, Bennell K, Dowsey $M$. Longitudinal changes in knee kinematics and moments following knee arthroplasty: a systematic review. Knee. 2014;21(6):994-1008; doi: 10.1016/j.knee. 2014.09.009.

23. Ewen AM, Stewart S, Gibson ASC, Kashyap SN, Caplan N. Post-operative gait analysis in total hip replacement patients - a review of current literature and metaanalysis. Gait Posture. 2012;36(1):1-6; doi: 10.1016/j. gaitpost.2011.12.024.

24. Creaby MW, Cole MH. Gait characteristics and falls in Parkinson's disease: a systematic review and meta-analysis. Parkinsonism Relat Disord. 2018; doi: 10.1016/j. parkreldis.2018.07.008.

25. Protas EJ, Mitchell K, Williams A, Qureshy H, Caroline K, Lai EC. Gait and step training to reduce falls in Parkinson's disease. NeuroRehabilitation. 2005;20(3):183-190.

26. Pau M, Leban B, Collu G, Migliaccio GM. Effect of light and vigorous physical activity on balance and gait of older adults. Arch Gerontol Geriatr. 2014;59(3):568-573; doi: 10.1016/j.archger.2014.07.008.

27. Awotidebe TO, Ativie RN, Oke KI, Akindele MO, Adedoyin RA, Olaogun MOB, et al. Relationships among exercise capacity, dynamic balance and gait characteristics of Nigerian patients with type-2 diabetes: an indication for fall prevention. J Exerc Rehabil. 2016;12(6):581-588; doi: 10.12965/jer.1632706.353.

28. Senden R, Grimm B, Heyligers IC, Savelberg HH, Meijer K. Acceleration-based gait test for healthy subjects: reliability and reference data. Gait Posture. 2009;30(2): 192-196; doi: 10.1016/j.gaitpost.2009.04.008.

29. Lythgo N, Wilson C, Galea M. Basic gait and symmetry measures for primary school-aged children and young adults whilst walking barefoot and with shoes. Gait Posture. 2009;30(4):502-506; doi: 10.1016/j.gaitpost.2009. 07.119.

30. Lythgo N, Wilson C, Galea M. Basic gait and symmetry measures for primary school-aged children and young adults. II: Walking at slow, free and fast speed. Gait
Posture. 2011;33(1):29-35; doi: 10.1016/j.gaitpost.2010. 09.017.

31. Leonardi L, Aceto MG, Marcotulli C, Arcuria G, Serrao M, Pierelli $F$, et al. A wearable proprioceptive stabilizer for rehabilitation of limb and gait ataxia in hereditary cerebellar ataxias: a pilot open-labeled study. Neurol Sci. 2017;8(3):459-463; doi: 10.1007/s10072-016-2800-x.

32. Bissolotti L, Passeri EV, Gaffurini P, Chiari S, Calabretto $\mathrm{C}$, Pivetti $\mathrm{S}$, et al. The functional gait analysis in persons with haemophilia: quantitative data from a newly designed triaxial accelerometer: P-234. Haemophilia. 2015;21(6):e553-e554.

33. Sabia S, Dumurgier J, Tavernier B, Head J, Tzourio C, Elbaz A. Change in fast walking speed preceding death: results from a prospective longitudinal cohort study. J Gerontol A Biol Sci Med Sci. 2014;69(3):354-362; doi: 10.1093/gerona/glt114.

34. Perera S, Mody SH, Woodman RC, Studenski SA. Meaningful change and responsiveness in common physical performance measures in older adults. J Am Geriatr Soc. 2006;54(5):743-749; doi: 10.1111/j.1532-5415.2006. 00701.x.

35. Quach L, Galica AM, Jones RN, Procter-Gray E, Manor B, Hannan MT, et al. The nonlinear relationship between gait speed and falls: the Maintenance of Balance, Independent Living, Intellect, and Zest in the Elderly of Boston study. J Am Geriatr Soc. 2011;59(6):1069-1073; doi: 10.1111/j.1532-5415.2011.03408.x.

36. Van Kan GA, Rolland Y, Andrieu S, Bauer J, Beauchet O, Bonnefoy M, et al. Gait speed at usual pace as a predictor of adverse outcomes in community-dwelling older people: an International Academy on Nutrition and Aging (IANA) Task Force. J Nutr Health Aging. 2009;13(10): 881-889 doi: 10.1007/s12603-009-0246-z.

37. Ruchlewicz T, Staszkiewicz R, Chwała W. Racewalking: how to save energy [in Polish]. Sport Wyczynowy. 2006; 3-4:40-50.

38. Hirose D, Ishida K, Nagano Y, Takahashi T, Yamamoto H. Posture of the trunk in the sagittal plane is associated with gait in community-dwelling elderly population. Clin Biomech. 2004;19(1):57-63; doi: 10.1016/j.clinbiomech. 2003.08.005.

39. Kerrigan DC, Lee LW, Collins JJ, Riley PO, Lipsitz LA. Reduced hip extension during walking: healthy elderly and fallers versus young adults. Arch Phys Med Rehabil. 2001;82(1):26-30; doi: 10.1053/apmr.2001.18584.

40. Sadeghi $H$, Allard $P$, Prince F, Labelle H. Symmetry and limb dominance in able-bodied gait: a review. Gait Posture. 2000;12(1):34-45; doi: 10.1016/S0966-6362(00)00070-9.

41. Chen Z, Maricic M, Aragaki AK, Mouton C, Arendell L, Lopez AM, et al. Fracture risk increases after diagnosis of breast or other cancers in postmenopausal women: results from the Women's Health Initiative. Osteoporos Int. 2009;20(4):527-536; doi: 10.1007/s00198-008-0721-0.

42. Siegel R, DeSantis C, Virgo K, Stein K, Mariotto A, Smith T, et al. Cancer treatment and survivorship statistics, 2012. CA Cancer J Clin. 2012;62(4):220-241; doi: 10.3322/caac.21149.

43. Bylow K, Dale W, Mustian K, Stadler WM, Rodin M, Hall W, et al. Falls and physical performance deficits in older patients with prostate cancer undergoing androgen deprivation therapy. Urology. 2008;72:422-427; doi: 10.1016/j.urology.2008.03.032.

44. Borzym A. Falls in old age - reasons, consequences, prophylaxis [in Polish]. Psychogeriatr Pol. 2009;6(2):81-88. 
45. Puts MT, Monette J, Girre V, Wolfson C, Monette M, Batist $\mathrm{G}$, et al. The fall rate of older community-dwelling cancer patients. Support Care Cancer. 2013;21(3):775783; doi: 10.1007/s00520-012-1579-4.

46. Schlairet MC, Benton MJ. Quality of life and perceived educational needs among older cancer survivors. J Cancer Educ. 2012;27(1):21-26; doi: 10.1007/s13187-0110279-y.

47. Cheville AL, Beck LA, Petersen TL, Marks RS, Gamble GL. The detection and treatment of cancer-related functional problems in an outpatient setting. Support Care Cancer. 2009;17(1):61-67; doi: 10.1007/s00520-008-0461-x.

48. Gewandter JS, Fan L, Magnuson A, Mustian K, Peppone L, Heckler C, et al. Falls and functional impairments in cancer survivors with chemotherapy-induced peripheral neuropathy (CIPN): a University of Rochester CCOP study. Support Care Cancer. 2013;21(7):20592066; doi: 10.1007/s00520-013-1766-y. 